\title{
1 When to stop drying fruit: insights from hygrothermal modelling
}

2 Thijs Defraeye ${ }^{a, b *}$

${ }^{a}$ Multiscale Studies in Building Physics, Empa, Überlandstrasse 129, 8600 Dübendorf, Switzerland

${ }^{b}$ Chair of Building Physics, ETH Zurich, Stefano-Franscini-Platz 5, 8093 Zürich, Switzerland

\section{* Corresponding author}

- E-mail thijs.defraeye@empa.ch

- Tel. $\quad+41(0) 587654790$

- Fax. +41446331041

11 Keywords: rehydration, convective, apple, hygrothermal, COMSOL, moisture redistribution

\section{Abstract}

14 Stopping the drying process prior to complete dehydration reduces energy consumption and processing time but can 15 also improve product quality. Using hygrothermal simulations, different stopping criteria are evaluated, which are 16 based on the final water activity and residual moisture content in the fruit. Their impact on drying time and moisture 17 redistribution kinetics inside fruit is quantified. One of the variants leads to a significant reduction in residence time 18 in the dryer (24\%), compared to full dehydration. For this variant, drying is stopped when the average moisture 19 content in the sample reaches the value corresponding to an equilibrium water activity of $60 \%$ in the sample, as 20 determined from the sorption isotherm. At the same time, this variant does not induce problems with fruit spoilage, 21 as a sufficiently low water activity is reached after moisture redistribution during relaxation in the ambient 22 environment. In addition, the relation of the drying time to the drying air temperature was quantified for all stopping 23 criteria, as well as the impact of the humidity of the ambient environment in which the dried fruits are placed 24 afterwards. This study gives a better quantitative insight in when fruit drying should be stopped, given specific drying conditions, without having to compromise food safety.

\section{Introduction}

27 Drying is one of the oldest and most important technologies for food preservation, including for fresh fruit [1].

28 Further optimization of such drying processes is essential to reduce the environmental impact of this energy29 intensive unit operation and to enhance product quality [2]. A key question here is when to stop the drying process. 30 Insufficient drying of fresh fruit leads to high water activity levels. These reduce shelf life and can cause spoilage, 
31 which leads to food safety risks. Typically fruits should be dried so their equilibrium water activity is below $60-65 \%$ $32[3]$.

33 To avoid problems, fruits are therefore often dried a bit too long. Overdrying however results in excessive energy use due to the longer duration of the drying process, and the additional energy used to evaporate the remaining water. The almost complete removal of moisture is however not required. The reason is that these fruits are afterwards brought to an ambient environment for further processing, packaging and storage. Due to the lower temperatures and often higher humidity than in the dryer, they will take up some moisture again. As such, the energy that was originally used to evaporate this water by drying, i.e. the latent heat needed to induce a phase change from liquid water to vapor, was spent in vain.

It is energetically more beneficial to stop the drying process earlier. It is feasible to do so while, at the same time, still achieving a sufficiently low water activity in the fruit to ensure food safety. To this end, the residual moisture in the fruit needs to redistribute or diffuse further out into the ambient environment during so-called equilibration, in order for the equilibrium water activity to fall below its critical value ( $60 \%)$. In such a way, all the water that is present in the final dried product was originally contained in the product instead of coming partially from its environment, so no energy has been wasted in removing it first by evaporation. Such equilibration after drying can take place in the food processing plant or inside the package. Finding the optimal time to stop drying is imperative to evolve to more energy-smart drying processes. Furthermore, excessive dehydration implies more shrinkage, which will probably not be entirely recovered during partial rehydration into the ambient environment. Hence, fruit quality aspects, such as structure, texture or mouthfeel, which determine palatability and consumer acceptance, can also be improved by halting the drying process earlier.

Recent research on drying of fresh-cut fruit evaluated, amongst others: (1) the impact of different process parameters, such as air speed, fruit size or environmental conditions [4-8]; (2) various process control strategies [9]; (3) the spatial heterogeneity of the moisture content within the sample during drying $[10,11]$; $(4)$ energetically more beneficial processes, including intermittent drying [12-14]. In most cases however, complete dehydration of the samples was considered. Typically, the drying time was taken the same for all cases, even though some samples dried out faster than others. The question on whether and when to stop the drying process earlier, which makes more sense from an energy or even quality point of view, was not the main target. This stopping time is however very case dependent. The impact of when to stop drying is not considered in most studies.

Determining an appropriate stopping time requires measurements of the water activity after equilibration. Water activity, not moisture content, is the suitable parameter to evaluate if fruits are sufficiently dry to ensure food safety and to guarantee sufficient shelf life. Moisture content, on the other hand, is often used as a criterion to assess if the drying process is finalized, namely by measuring gravimetrically if a sample is fully dry. Water activity is related to the moisture content via the sorption isotherm, so if the latter is known, water activities can be estimated from moisture content measurements in principle. Nevertheless, measuring both water activity and moisture content 
$h_{l} \frac{\partial w_{m}}{\partial \psi} \frac{\partial \psi}{\partial t}+\left(c_{p, s} w_{s}+c_{p, l} w_{m}\right) \frac{\partial T}{\partial t}+\nabla \cdot\left(-h_{l} K_{m} \nabla \psi\right)+\nabla \cdot\left(-\lambda_{P M} \nabla T\right)=0$ is usually monitored gravimetrically in drying studies. quality products.

\section{Materials and methods}

\subsection{Continuum model for fruit tissue} shrinking and swelling of the tissue are not modelled.

\section{Conservation equations}

$\frac{\partial w_{m}}{\partial \psi} \frac{\partial \psi}{\partial t}+\nabla \cdot\left(-K_{m} \nabla \psi\right)=0$

experimentally at different points in time during drying is tedious and rather labor-intensive, especially if various drying conditions need to be evaluated. Therefore, only the moisture content, and not the water activity in the fruit,

As an alternative, this study relies on numerical hygrothermal modelling of the drying process to explore what the impact is of stopping the process before complete dehydration. To this end, we monitor how the moisture distribution within the fruit evolves during and after drying, including the moisture redistribution kinetics during equilibration in the ambient environment. Different stopping criteria are evaluated, namely based on the water activity or the residual moisture content in the sample. We also explore the impact of the humidity level of the ambient environment in which the dried fruit is placed after drying. This study gives a better quantitative insight in when fruit drying should be stopped for specific drying conditions, in order to save energy and to obtain higher

A validated continuum model was developed previously [15] to calculate the heat and moisture transfer in fruit tissue during drying. Only its main characteristics are highlighted below and more details can be found elsewhere [15]. The main model assumptions are that evaporation is assumed to occur only at the tissue surface and that

The following conservation equations for moisture and energy are solved to the dependent variables temperature $T$ $[\mathrm{K}]$ and water potential $\psi[\mathrm{Pa}]$, which are the driving potentials for heat and moisture transport in the fruit tissue:

where $w_{s}$ and $w_{m}$ are the dry matter density (solid) and moisture content of the tissue $\left[\mathrm{kg} \mathrm{m}^{-3}\right]$, respectively. $K_{m}$ is the moisture permeability of the tissue $[\mathrm{s}], h_{l}$ is the enthalpy of liquid water $\left[\mathrm{J} \mathrm{kg}^{-1}\right], \lambda_{P M}$ is the thermal conductivity of the tissue (porous medium) $\left[\mathrm{W} \mathrm{m}^{-1} \mathrm{~K}^{-1}\right], c_{p, s}$ and $c_{p, l}$ are the specific heat capacities of dry matter and liquid water $\left[\mathrm{J} \mathrm{kg}^{-1} \mathrm{~K}^{-}\right.$ $\left.{ }^{1}\right]$, respectively.

These material properties are given in Table 1. $K_{m}$ and the sorption isotherm are taken from [16]. Although the permeability can change as a function of moisture content, it is challenging to determine this relation accurately. The variability in permeability induced by harvest year or harvest location can even be larger than the variation of the 
permeability with moisture content. The numerical model (with a constant permeability) was validated [15] and matched the experimental data well. In the energy conservation equation, the impact of the first and third term on

97 the left-hand side is actually very low in the present study due to the low drying rates. These terms are not 98 accounted for usually [17]. The water potential is related to the water activity $a_{w}$ by:

100 The water activity in turn is related to the moisture content $w_{m}$ via the sorption isotherm (see Table 1 ), namely $w_{m}$

101 vs. $a_{w}$. From the sorption isotherm, the moisture capacity $C_{m}=\frac{\partial w_{m}}{\partial \psi}$ can be determined.

\section{Boundary conditions}

103 The boundary conditions at the air-tissue interface (continuity of fluxes) are specified as:

$\mathbf{n} \cdot\left(-\mathrm{K}_{\mathrm{m}} \nabla \psi\right)=\mathrm{g}_{\mathrm{m}}=\mathrm{h}_{\mathrm{c}, \mathrm{m}}\left(\mathrm{p}_{\mathrm{v}, \mathrm{w}}-\mathrm{p}_{\mathrm{v}, \mathrm{ref}}\right)$

$\mathbf{n} \cdot\left(-\mathrm{h}_{\mathrm{l}} \mathrm{K}_{\mathrm{m}} \nabla \psi-\lambda_{\mathrm{PM}} \nabla \mathrm{T}\right)=\mathrm{g}_{\mathrm{T}}=\left(\mathrm{h}_{\mathrm{c}, \mathrm{T}}\left(\mathrm{T}_{\mathrm{w}}-\mathrm{T}_{\mathrm{ref}}\right)-\mathrm{h}_{\mathrm{v}} \mathrm{g}_{\mathrm{m}}\right)$

106 where $g_{m}\left[\mathrm{~kg} \mathrm{~m}^{-2} \mathrm{~s}^{-1}\right]$ and $g_{T}\left[\mathrm{~J} \mathrm{~m}^{-2} \mathrm{~s}^{-1}\right]$ are the mass and heat fluxes at the interface, $\mathbf{n}$ is the unit vector normal to the 107 interface, $h_{c, m}$ is the convective mass transfer coefficient (CMTC $\left[\mathrm{s} \mathrm{m}^{-1}\right]$ ), $h_{c, T}$ is the convective heat transfer coefficient 108 (CHTC $\left.\left[\mathrm{W} \mathrm{m}^{-2} \mathrm{~K}^{-1}\right]\right), p_{v, w}$ and $p_{v, r e f}$ are the vapor pressures at the interface and of the ambient air [Pa], $T_{w}$ and $T_{\text {ref }}$ are 109 the temperatures at the interface and of the ambient air [K], $h_{v}$ and $h_{l}$ are the enthalpies of water vapor and liquid water $\left[\mathrm{Jg}^{-1}\right]$.

111 For mass transfer, the boundary condition states that the moisture loss from the tissue equals the convective vapor

112 removal from the surface. For heat transfer, the boundary condition states that heat loss from the tissue, due to 113 conduction and liquid water transport, equals the convective (sensible) heat exchange with the environment and the 114 heat removal due to the water vapor loss, including evaporation. In the present study, long-wave radiation exchange 115 of the tissue with the environment via the surface is not modelled. 
Table 1. Material properties, boundary conditions and initial conditions for the base case.

\begin{tabular}{|c|c|c|}
\hline Material properties & Symbol & Value \\
\hline Moisture permeability fruit tissue & $K_{m}$ & $8 \times 10^{-16}[\mathrm{~s}]$ \\
\hline Thermal conductivity fruit tissue & $\lambda_{P M}$ & $0.418\left[\mathrm{~W} \mathrm{~m}^{-1} \mathrm{~K}^{-1}\right]$ \\
\hline Specific heat capacity of dry matter & $c_{p, s}$ & $1634\left[\mathrm{~J} \mathrm{~kg}^{-1} \mathrm{~K}^{-1}\right]$ \\
\hline Specific heat capacity of liquid water & $c_{p, l}$ & $4182\left[\mathrm{~J} \mathrm{~kg}^{-1} \mathrm{~K}^{-1}\right]$ \\
\hline Specific heat capacity water vapor & $c_{p, v}$ & $1880\left[\mathrm{~J} \mathrm{~kg}^{-1} \mathrm{~K}^{-1}\right]$ \\
\hline Dry matter content & $w_{s}$ & $130\left[\mathrm{~kg} \mathrm{~m}^{-3}\right]$ \\
\hline Sorption isotherm & $w_{m}\left(a_{w}\right)$ & $w_{s}\left(\frac{0.15926}{\ln \left(\frac{1.0177}{a_{w}}\right)}\right)^{\frac{1}{0.97014}}\left[\mathrm{~kg} \mathrm{~m}^{-3}\right]$ \\
\hline Density liquid water & $\rho_{l}$ & $1000\left[\mathrm{~kg} \mathrm{~m}^{-3}\right]$ \\
\hline Latent heat & $L_{v}$ & $2.5 \times 10^{6}\left[\mathrm{~J} \mathrm{~kg}^{-1}\right]$ \\
\hline Specific gas constant for water vapor & $R_{v}$ & $461.52\left[\mathrm{~J} \mathrm{~kg}^{-1} \mathrm{~K}^{-1}\right]$ \\
\hline Boundary and initial conditions & Symbol & Value \\
\hline Initial tissue temperature & $T_{\text {ini }}$ & $20\left[{ }^{\circ} \mathrm{C}\right]$ \\
\hline Initial tissue moisture content (dry base) & $X_{i n i}$ & $6\left[\mathrm{~kg} \mathrm{~kg}_{\mathrm{dm}}^{-1}\right]$ \\
\hline Initial tissue moisture content & $w_{m, i n i}$ & $780\left[\mathrm{~kg} \mathrm{~m}^{-3}\right]$ \\
\hline Air temperature during drying & $T_{r e f, d}$ & $20^{\circ} \mathrm{C}$ \\
\hline Relative humidity during drying & $R H_{r e f, d}$ & $30 \%$ \\
\hline Convective heat transfer coefficient during drying & $h_{c, T}$ & $100\left[\mathrm{~W} \mathrm{~m}^{-2} \mathrm{~K}^{-1}\right]$ \\
\hline Convective mass transfer coefficient during drying & $h_{c, m}$ & $7.03 \times 10^{-7}\left[\mathrm{~s} \mathrm{~m}^{-1}\right]$ \\
\hline
\end{tabular}

\section{Constitutive equations}

120 The enthalpies of water vapor and liquid water, $h_{\nu}$ and $h_{l}\left[\mathrm{~J} \mathrm{~kg}^{-1}\right]$, are:

$121 \mathrm{~h}_{\mathrm{l}}=\mathrm{c}_{\mathrm{p}, \mathrm{l}}\left(\mathrm{T}-\mathrm{T}_{\mathrm{ref}, 0}\right)$

122

$\mathrm{h}_{\mathrm{v}}=\mathrm{c}_{\mathrm{p}, \mathrm{v}}\left(\mathrm{T}-\mathrm{T}_{\mathrm{ref}, 0}\right)+\mathrm{L}_{\mathrm{v}}$

123 where $L_{v}$ is the heat of vaporization $\left[\mathrm{J} \mathrm{kg}^{-1}\right]$, also called latent heat, which is the energy needed for the phase change

124 from liquid to vapor. $T_{\text {ref,o }}$ is a reference temperature, taken equal to $273.15 \mathrm{~K}\left(0^{\circ} \mathrm{C}\right)$. 
126 The vapor pressures $p_{v, w}$ and $p_{v, \text { ref }}$ are determined based on the water activity at the interface $\left(a_{w, w}\right)$ and the relative

127 humidity of the drying or ambient air $\left(R H_{r e f}\right)$, together with the corresponding temperatures, via the saturated vapor 128 pressure $\left(p_{v, s a t}[\mathrm{~Pa}]\right)$ :

$129 p_{v, \mathrm{w}}=a_{w, \mathrm{w}} p_{v, \mathrm{sat}}\left(T_{w}\right)$

$p_{v, \text { ref }}=R H_{r e f} p_{v, \text { sat }}\left(T_{r e f}\right)$

$p_{v, \text { sat }}(T)=e^{65.8094-\frac{7066.27}{T}-5.976 \ln T}$

\subsection{Configuration and computational model}

134 The configuration used to evaluate convective drying of fresh-cut apple tissue is a cubic piece (length $L_{c}=20 \mathrm{~mm}$ ) suspended in the surrounding air. This study departs from apple fruit, as it is a frequently applied material to study fruit drying with a significant economic relevance. A base case is simulated, namely full dehydration, as well as other variants, which evaluate partial dehydration for different stopping criteria and for different environmental conditions.

\section{Base case}

The computational model and the imposed boundary conditions are specified in Figure 1. A 3D model of the fruit is used, but only one eighth of the cube is modelled due to symmetry. The apple fruit is of the cultivar Braeburn. The relevant material properties and boundary/initial conditions used for modelling are specified in Table 1. The fruit is assumed to be initially (fresh-cut state) at a uniform moisture content $w_{m, i n i}$ of $780 \mathrm{~kg} \mathrm{~m}^{-3}$ at a uniform temperature $T_{\text {ini }}$ of $20^{\circ} \mathrm{C}$. This moisture content leads to a dry base moisture content $X_{i n i}$ of $6\left(=w_{m, i n i} / w_{s}\left[\mathrm{~kg} \mathrm{~kg}_{\mathrm{dm}}{ }^{-1}\right]\right)$.

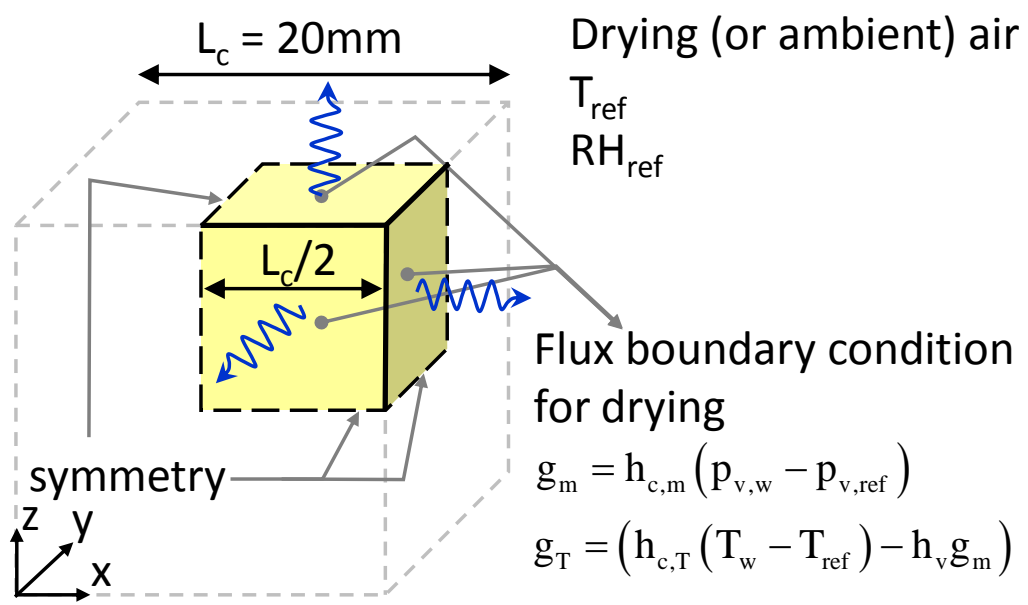


The airflow around the cube is not modelled explicitly, but its impact on the drying process is accounted for by the use of convective transfer coefficients (CTCS). The same CTC value is applied on all sides of the cube. This is a simplified representation as a spatial CTC variation between the sides of the cube exists in reality for forced convection $[11,18]$. Within the scope of this study, including such a spatial variation is not of interest as it will not affect the main outcome of the study. Also note that the CTCs are taken constant in time, which implies, amongst others, that the air speed remains constant during drying, which is normally the case for forced convective drying. The ambient air during drying is kept at a constant temperature $\left(T_{\text {ref,d }}\right)$ and relative humidity $\left(R H_{r e f, d}\right)$. The convective heat transfer coefficient is $100 \mathrm{~W} \mathrm{~m}^{-2} \mathrm{~K}^{-1}$ for the base case, which is typical for forced convective drying. The CMTC is estimated from the CHTC using the heat and mass transfer analogy, similar as in [19], leading to a ratio CMTC/CHTC (analogy factor) of $7.03 \times 10^{-9}$.

An appropriate grid is built for the porous material, based on a grid sensitivity analysis. The grid consists of 64000 hexahedral finite elements, namely 40 divisions on each side $\left(1 / 8^{\text {th }}\right)$ of the cube. A gradual refinement towards the air-tissue interface is applied to enhance numerical accuracy and stability as the largest gradients occur here, particularly at the start of the drying process.

\section{Variants}

Various cases of partial dehydration are simulated (Table 2). A first type evaluated three different stopping criteria for the drying process, namely:

- Var1_WAavg: Stopping when the (volume-)averaged water activity in the sample reaches $60 \%$, as the latter is the critical equilibrium water activity below which no spoilage occurs $\left(a_{w, c r i t}\right)$ for dried fruit [3].

- Var2_WAcore: Stopping when the water activity in the core of the sample reaches $60 \%$.

- Var3_MCavg: Stopping when the (volume-)averaged moisture content in the sample reaches the critical moisture content $\left(w_{m, c r i t}\right)$. The latter is defined as the moisture content that corresponds, via the fruit sorption isotherm (Figure 2 ), to an equilibrium water activity of $60 \%\left(a_{w, c r i t}\right)$. In principle, if the drying process is stopped at $w_{m, \text { crit }}$ and the sample is equilibrated in an ambient environment where the relative humidity equals $a_{w, \text { crit }}$ or lower, the average final water activity in the tissue will be below $a_{w, c r i t}$. This was verified by numerical simulations as well (results not reported). For the present study, $w_{m, \text { crit }}$ was $37.8 \mathrm{~kg} \mathrm{~m}^{-3}$, leading to an $X_{\text {crit }}$ of $0.29 \mathrm{~kg} \mathrm{~kg} \mathrm{dm}^{-1}$. 


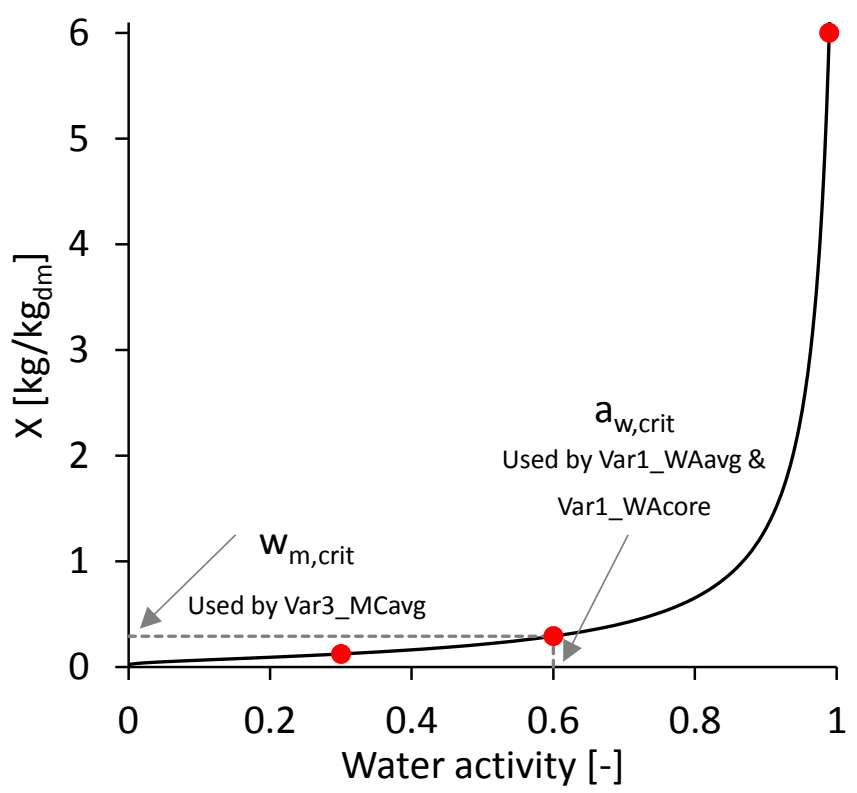

Figure 2. Sorption isotherm for apple fruit (cv. Braeburn, from [16]). The red dots indicate the initial water activity (fresh tissue), and a water activity of $30 \%$ and $60 \%$.

For this type of simulations, the times at which these stopping conditions are met, are extracted from the base case simulation (see Table 2). Afterwards, separate simulations are run for each variant, which involve partial dehydration until the stopping criterion. After stopping the drying process, each sample is placed in a low convection environment ( $\mathrm{CHTC}=10 \mathrm{~W} \mathrm{~m}^{-2} \mathrm{~K}^{-1}$, and CMTC changes accordingly) at ambient conditions, in which the sample can equilibrate with the environment. The humidity of this environment is chosen to equal the critical equilibrium water activity $\left(a_{w, c r i t}=60 \%\right)$ necessary to avoid spoilage. This change in environmental conditions is implemented as a step

184 function. A smoothing function was applied to achieve a gradual transition from one environment to the other, with 185 a transition time of $10 \mathrm{~min}$. The sensitivity to smaller transition times (e.g. $1 \mathrm{~min}$ ) was found to be very small.

186 A second type of simulations involves evaluating the base case for higher drying temperatures, in order to quantify 187 how the stopping times are affected by temperature. To determine these stopping times, only the complete drying process needed to be simulated. A third type of simulations evaluates what happens if the samples are placed in an ambient environment with lower humidity $(<60 \%)$, after partial dehydration, and if this positively affects the drying time. 


\begin{tabular}{|c|c|c|c|c|c|c|c|}
\hline \multirow[b]{2}{*}{ Name } & \multicolumn{3}{|l|}{ Drying process } & \multirow{2}{*}{$\begin{array}{l}\text { Time drying is } \\
\text { stopped } \\
\text { [hours] }\end{array}$} & \multicolumn{3}{|l|}{ Storage process } \\
\hline & 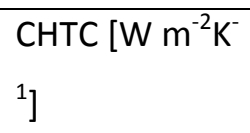 & $\begin{array}{l}R H_{r e f, d} \\
{[\%]}\end{array}$ & $\begin{array}{l}T_{\text {ref, } d} \\
{\left[{ }^{\circ} \mathrm{C}\right]}\end{array}$ & & 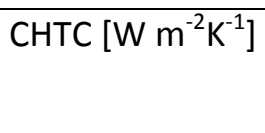 & $R H_{r e f, a}[\%]$ & $\begin{array}{l}T_{\text {ref, } a} \\
{\left[{ }^{\circ} \mathrm{C}\right]}\end{array}$ \\
\hline Base case & 100 & 30 & 20 & n.a. & n.a. & n.a. & n.a. \\
\hline \multicolumn{8}{|l|}{ Stopping criterion } \\
\hline Var1_WAavg & - & - & - & 12.1 & 10 & 60 & 20 \\
\hline Var2_WAcore & - & - & - & 39.4 & 10 & 60 & 20 \\
\hline Var3_MCavg & - & - & - & 30.8 & 10 & 60 & 20 \\
\hline \multicolumn{8}{|l|}{ Drying temperature } \\
\hline Base_Tref30C & - & - & 30 & n.a. & n.a. & n.a. & n.a. \\
\hline Base_Tref40C & - & - & 40 & n.a. & n.a. & n.a. & n.a. \\
\hline Base_Tref60C & - & - & 60 & n.a. & n.a. & n.a. & n.a. \\
\hline Base_Tref80C & - & - & 80 & n.a. & n.a. & n.a. & n.a. \\
\hline \multicolumn{8}{|l|}{$\begin{array}{l}\text { Ambient environment } \\
\text { after drying }\end{array}$} \\
\hline Var1_WAavg_RHref45 & - & - & - & 12.1 & - & 45 & - \\
\hline Var2_WAcore_RHref45 & - & - & - & 39.4 & - & 45 & - \\
\hline Var3_MCavg_RHref45 & - & - & - & 30.8 & - & 45 & - \\
\hline Var1_WAavg_RHref15 & - & - & - & 12.1 & - & 15 & - \\
\hline Var2_WAcore_RHref15 & - & - & - & 39.4 & - & 15 & - \\
\hline Var3_MCavg_RHref15 & - & - & - & 30.8 & - & 15 & - \\
\hline
\end{tabular}

\subsection{Numerical simulations}

196 This hygrothermal continuum model was implemented in COMSOL Multiphysics (version 5.0), which is a finite-

197 element based solver. The partial differential equations interface (coefficient form) was used, in which the

198 aforementioned conservation equations were implemented. Transient simulations simulated a drying process of 100 hours, starting from the specified initial conditions. Such a long simulation time is needed as drying is performed at low temperatures and since we want to monitor the fruit dehydration as well for a sufficiently long time after the 
201 active drying process is stopped. All simulations applied adaptive time stepping, as determined from a temporal

202 sensitivity analysis. The tolerances for convergence and other solver settings were determined based on sensitivity

203 analysis as well. A fully coupled solver was used to solve to the dependent variables $\psi$ and $T$. The simulations were

204 performed on a 12 core Intel Xeon processor $(2 \times 3.47 \mathrm{GHz})$ with 48GB RAM memory.

\section{Results and discussion}

\subsection{Stopping criterion for drying process}

207 The drying process for the base case and for the three stopping criteria (Table 2) are compared in Figure 3. The main 208 advantage of the simulations, compared to experiments, is that values at the surface of the fruit are available, such 209 as the mass flux and relative humidity. As they assist in interpreting the data and gaining insight in the drying 210 process, they are also depicted in Figure 3. The mass loss (change in dry matter moisture content, $X=w_{m} / w_{s}$ ) and 211 drying rate are shown versus time, as well as the surface-averaged temperature and relative humidity (or water 212 activity) at the air-tissue interface. Note that the drying rate equals the mass flux at the surface. The volume213 averaged fruit temperature was very similar to the surface temperature, which is why it is not depicted. The base 214 case is indicated with a bold black line. The dotted vertical lines indicate the stopping time for each variant. 

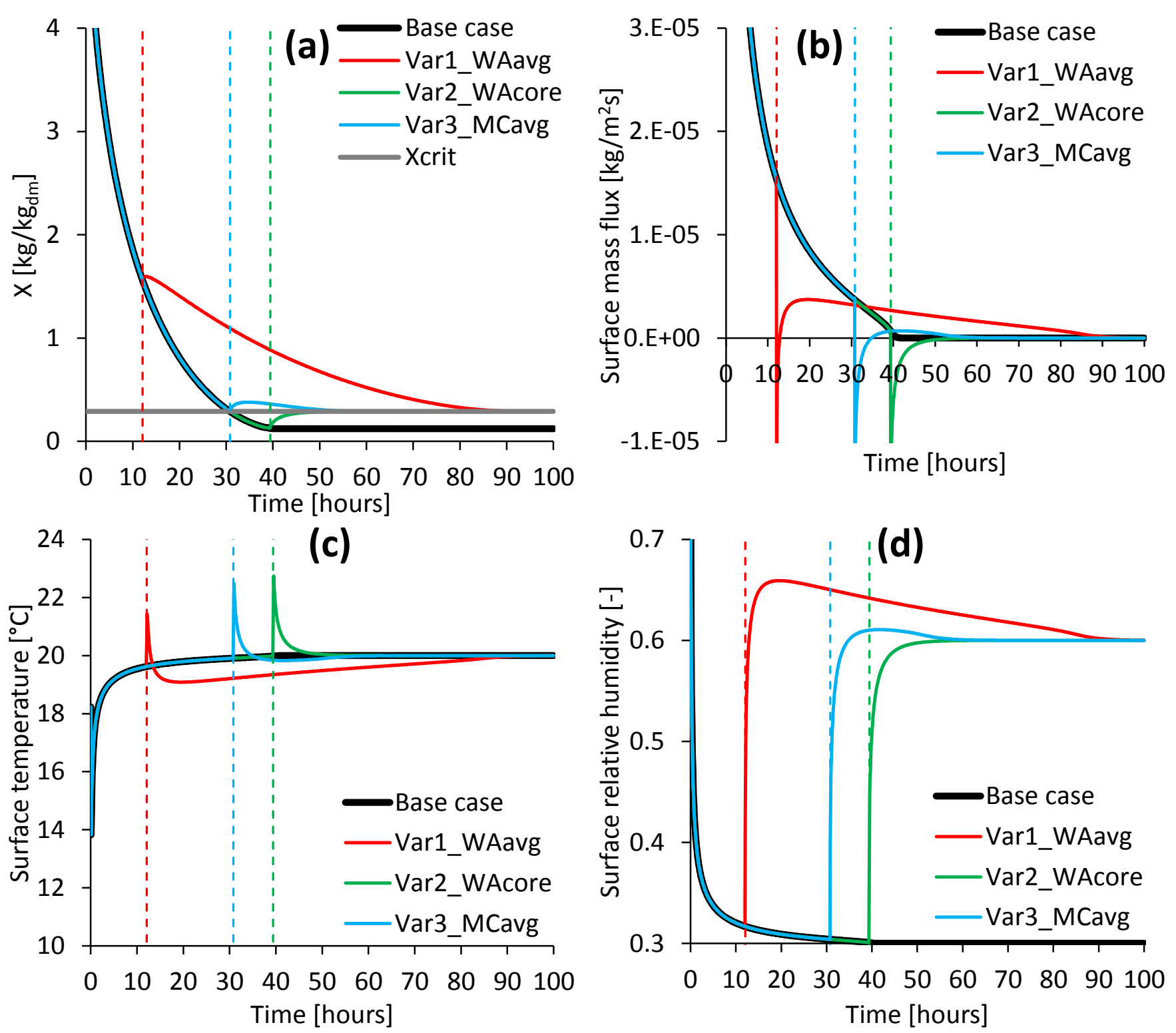

Figure 3. Comparison of drying process simulations of the base case and three different stopping criteria: Dry matter moisture content, including the critical moisture content $X_{\text {crit }}(a)$, drying rate $(b)$, temperature at the surface of the fruit (c) and corresponding relative humidity (or water activity) at the surface of the fruit (d), as a function of time. The dotted vertical lines indicate the stopping time for each variant.

The three stopping criteria clearly induce a different drying behavior. As indicated in Figure 3a, the earliest stopping time occurs for Var1_WAavg, namely if the volume-averaged water activity in the sample equals $a_{w, c r i t}(60 \%)$. The reason for this is the highly nonlinear sorption isotherm (Figure 2): even if a large part of the sample is at very low water activity, its average moisture content is still quite high. The subsequent stopping time occurs for variant Var3_MCavg, so if the average moisture content in the sample reaches a critical value, namely the moisture content corresponding to a water activity of $60 \%\left(a_{w, c r i t}\right)$. This critical moisture content is extracted via the sorption isotherm at $a_{w, c r i t}$. For a linear sorption isotherm, Var1_WAavg and Var3_MCavg would lead to the same stopping time. The longest duration before stopping the drying process is found for Var2_WAcore. In this case, the drying process is 
stopped if the water activity in the core of the sample equals $60 \%\left(a_{w, c r i t}\right)$. As the core holds the highest value of the water activity throughout the drying process, this obviously leads to the longest drying time.

230 For all stopping criteria, the sample takes up some moisture from the environment right after ending the convective 231 drying process. This is indicated by an increase in moisture content (Figure 3a), a negative drying rate (Figure 3b) and 232 an increase in temperature (Figure 3c) due to latent heat release from absorption. The reason for such uptake is that 233 the tissue near the surface is at a very low water activity. When it is brought into contact with a higher relative 234 humidity environment, moisture absorption is induced. Note that for higher drying temperatures $\left(T_{\text {ref, } d}\right)$, a very similar behavior as in Figure 3 is found (results not shown), except for the surface temperature of course.

A safe moisture content to stop the drying process is $w_{m \text {, crit }}$ since, if the sample is equilibrated in a sufficiently low $\mathrm{RH}$ environment, the average final water activity in the tissue will be below $a_{w, \text { crit. }}$. From Figure 3 , we clearly see that if the drying process is stopped early (Var1_WAavg), namely when the volume-averaged water activity in the sample equals $60 \%$, the drying time to reach a safe moisture content $\left(w_{m, \text { crit }}\right)$ is about twice as large as the one for Var3_MCavg, namely when the average moisture content in the sample reaches the critical moisture content. From a food safety perspective, such extensive drying time could become problematic but this aspect should be addressed separately by experiments.

243 On the other hand, if the sample is dried to much (Var2_WAcore), so below $w_{m, \text { crit, }}$ significant moisture uptake occurs 244 after drying, namely up to $w_{m}=w_{m}\left(R H_{r e f, a}\right)$ which equals $w_{m, \text { crit }}$ in this case. As a part of the final moisture present in the fruit did not have to be removed by convective drying, such overdrying is energetically not efficient. From these results, the most logical stopping criterion is drying until $w=w_{m, \text { crit, }}$, so Var3_MCavg (blue line in Figure 3 ). This stopping time should also pose no problems with food safety as equilibration within the sample to a safe water activity occurs rather fast. Stopping when the (volume-)averaged moisture content in the sample reaches the critical moisture content seems a good compromise between reducing drying time and ensuring food safety.

251 The dry base moisture content and the water activity inside the sample at different points in time are shown in 252 Figure 4 and Figure 5 for the base case and the variants. For all cases, moisture redistribution inside the sample clearly occurs after the drying process is stopped. The temperature distribution is not shown as the gradients within the sample were very low due to the rather slow mass transfer process compared to the heat transfer kinetics. 

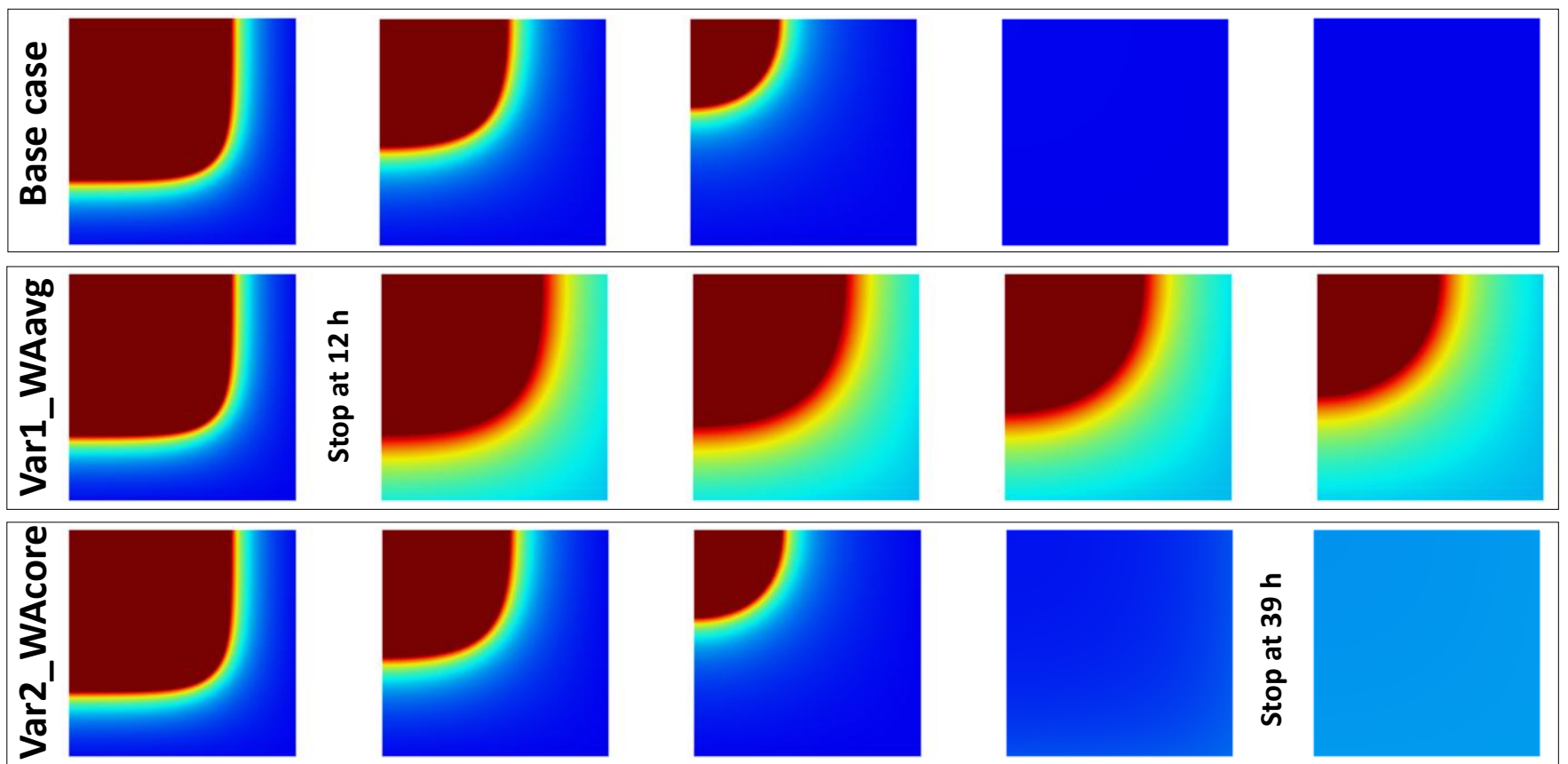

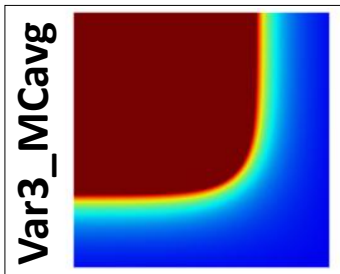

10 hours

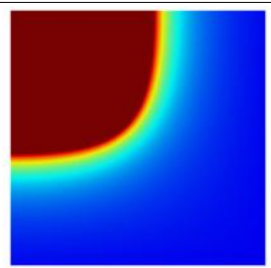

20 hours

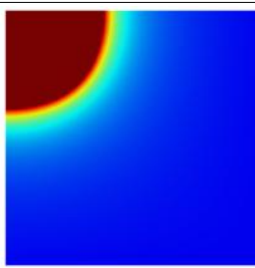

30 hours

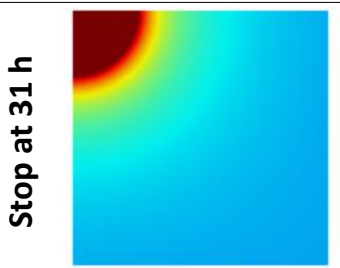

40 hours
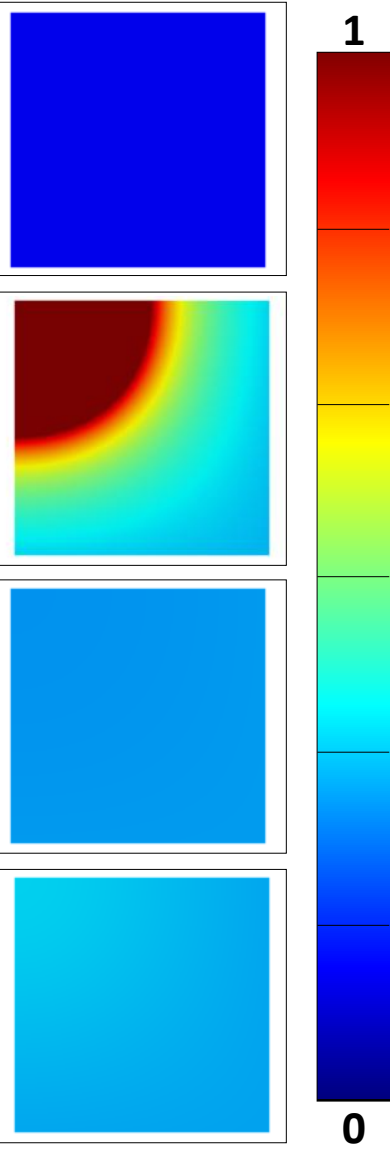

50 hours

256 Figure 4. Dry matter moisture content $X\left(\right.$ range $\left.0-1 \mathrm{~kg} \mathrm{~kg}_{d m}^{-1}\right)$ in a center plane of the cube (1/4 of cube depicted 257 due to symmetry) for the base case and the three variants at different points in time. 

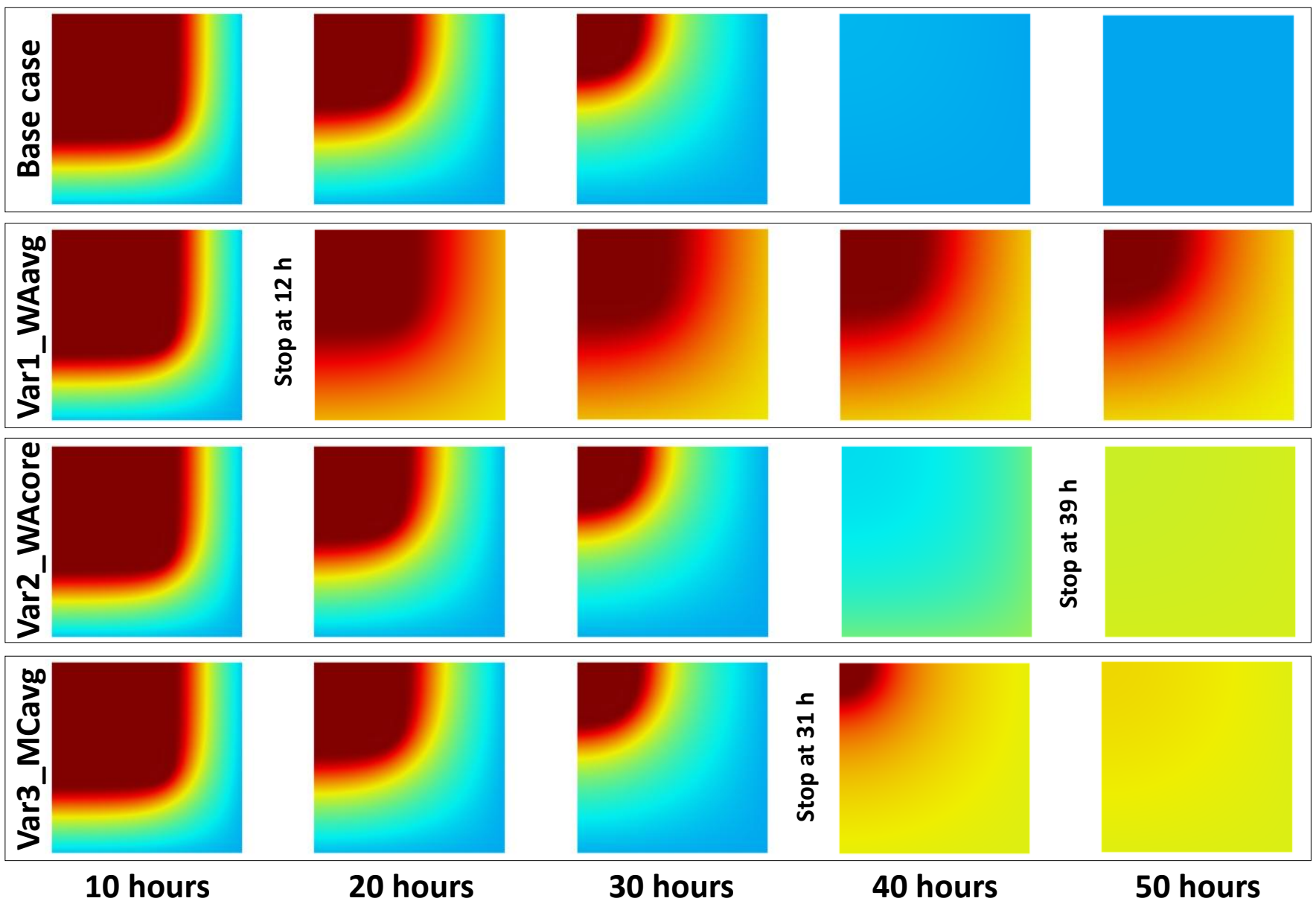

Figure 5. Water activity $a_{w}$ (range $\left.0-1\right)$ in a center plane of the cube (1/4 of cube depicted due to symmetry) for the base case and the three variants at different points in time. 


\subsection{Impact of drying temperature}

263 The impact of the drying air temperature on the magnitude of the aforementioned stopping times is evaluated. To 264 this end, simulations similar to the base case, but at higher drying temperature $\left(T_{\text {ref, }, d}\right)$, are performed (Table 2). The stopping time for each criterion is evaluated for each temperature and represented in Figure 6. The stopping time for each variant is presented relative to that of the corresponding variant at $20^{\circ} \mathrm{C}$ (Figure $6 \mathrm{a}, t_{s} / t_{s, 20^{\circ}} \mathrm{C}$ ), and relative to the time until the sample is fully dry at each corresponding temperature (Figure $6 \mathrm{~b}, t_{s} / t_{s, d r y}$ ). Fully dry is defined here as the time when the moisture content does not change significantly anymore compared to the final moisture content,

269 i.e. with less than $0.1 \mathrm{~kg} \mathrm{~m}^{-3}$ difference.

270 From Figure 6a, each stopping criterion has a different dependency on the drying temperature, where in general the 271 process can be stopped earlier when a higher drying temperature is used. Var2_WAcore and Var3_MCavg have a 272 very similar behavior, since they both occur close to the end of the drying process. From Figure $6 \mathrm{~b}$, the time that a 273 fruit has to spend in the dryer, compared to when it is fully dried, is much lower for Var3_MCavg, namely when the 274 average moisture content in the sample reaches the critical moisture content. However, a particularly low drying 275 time is found for Var1_WAavg for each $T_{\text {ref,d, }}$, namely the case when the (volume-)averaged water activity in the 276 sample reaches $60 \%$. The drying time is roughly $25 \%$ and $70 \%$ lower for Var3_MCavg and Var1_WAavg respectively.

277 Such a reduced residence time in the dryer still leads to a sufficiently dry product, but significantly increases

278 throughput and can reduce energy consumption. For Var2_WAcore on the other hand, i.e. when drying is stopped if 279 the water activity in the core of the sample equals $60 \%$, the fruit is already quite dry.

280 The representation used in Figure $6 \mathrm{a}$ is useful to compare drying processes at different conditions in a quantitative 281 way, since a drying curve can be represented by a single characteristic value, namely the stopping time $t_{s}$. For 282 Var3_MCavg, the stopping time equals the critical drying time $\left(t_{c r i t}\right)$, as it is the time needed for the sample to reach the critical moisture content $\left(w_{m, \text { crit }}\right)$. This $w_{m, \text { crit }}$ can serve as a useful parameter to decide to stop a drying process. 

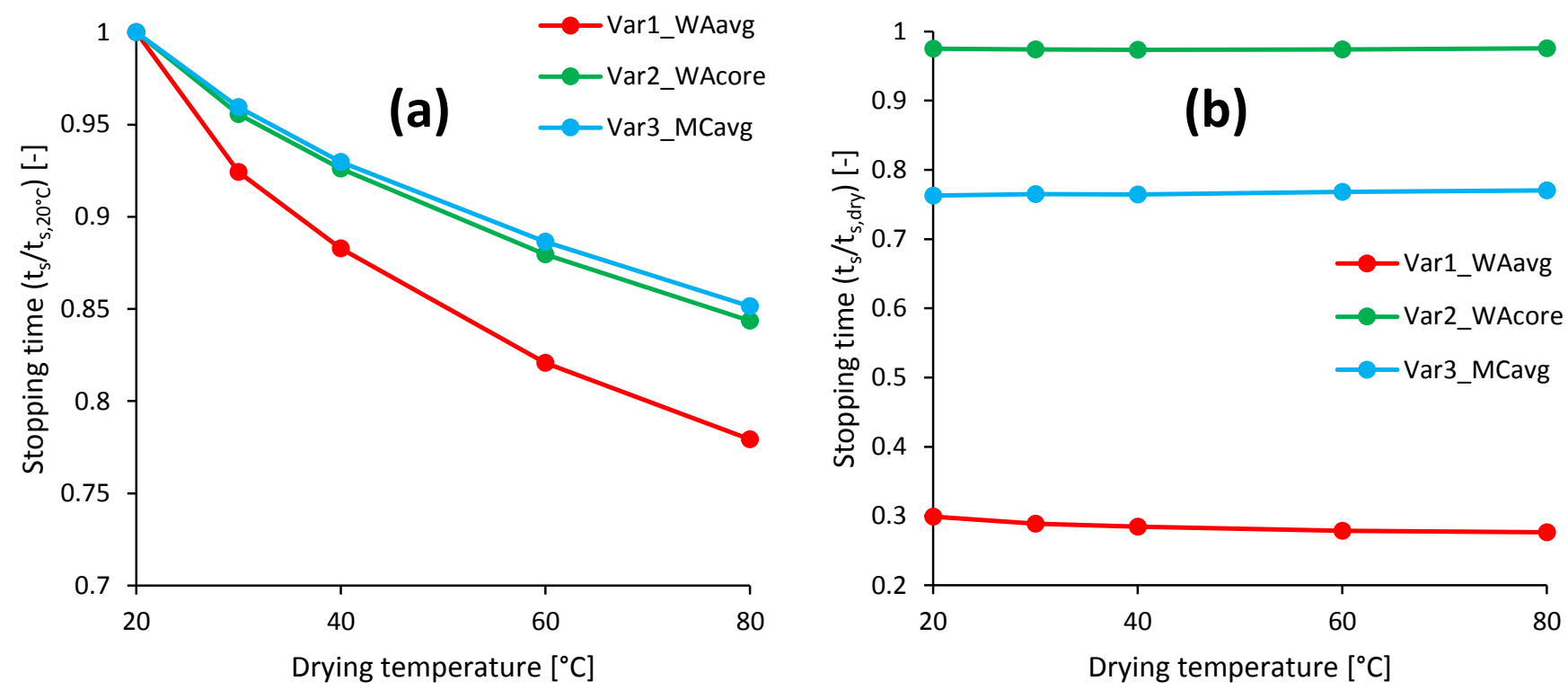

Figure 6. Stopping time at different drying temperatures for three stopping criteria: (a) relative to stopping time at $20^{\circ} \mathrm{C}$ for each variant; (b) relative to the time when sample is fully dry at each corresponding drying temperature.

\subsection{Impact of ambient environment after drying}

288 The impact of the ambient environment in which the sample is placed after partial dehydration is evaluated in Figure

2897 for three different stopping criteria. Two lower $R H_{\text {ref, } a}$ are considered, namely $45 \%$ and $15 \%$. These environments

290 represent for example a storage room, the ambient environment in the food processing plant, or the package. Note

291 that if samples are placed in a closed container or package, the humidity of the environment will increase with time,

292 and will thus not be constant. Similar to Figure 3 , the dry matter moisture content $\left(X=w_{m} / w_{s}\right)$ and drying rate are

293 shown versus time, as well as the surface-averaged temperature and relative humidity (or water activity) at the air-

294 tissue interface.

295 When placed in a 45\% environment, the graphs look similar to Figure 3. Obviously however, placing the sample in 296 such a drier environment after drying is beneficial for reaching a safe water activity earlier. When placed in a very dry 297 environment $\left(R H_{r e f, a}=15 \%\right)$, the fruit even reaches a higher drying rate than the base case over the majority of the 298 time $\left(R H_{r e f, a}=30 \%\right)$ and no noticeable moisture adsorption occurs when the drying process is stopped. In addition, 299 the larger evaporation rate induces a clear temperature drop. 

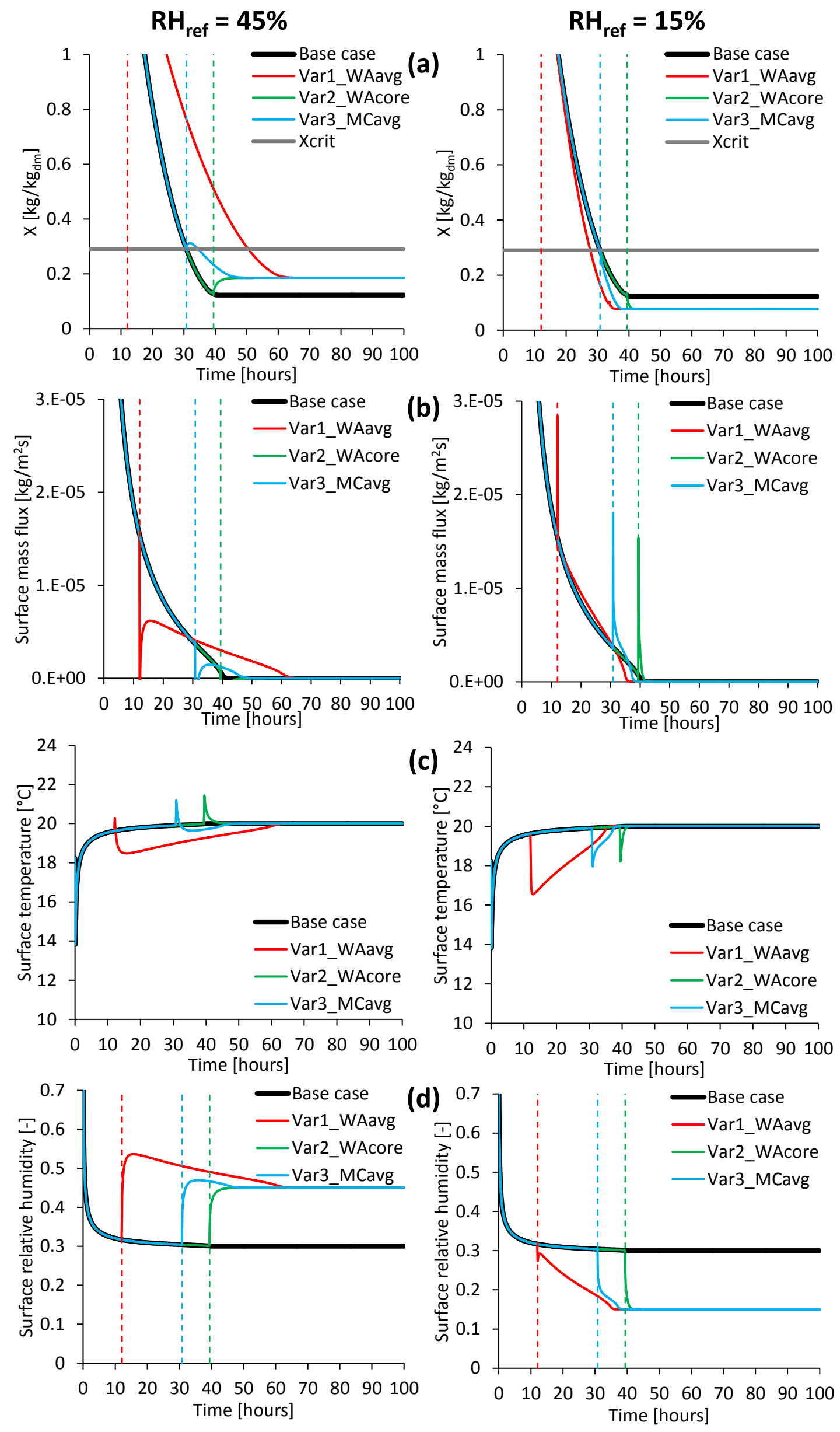
Figure 7. Comparison of drying process simulations of the base case and three different stopping criteria for two relative humidities of the ambient environment: Dry matter moisture content, including the critical moisture content $X_{\text {crit }}(a)$, drying rate (b), temperature at the surface of the fruit (c) and corresponding relative humidity (or water activity) at the surface of the fruit (d), as a function of time. The dotted vertical lines indicate the stopping time for each variant.

\subsection{Discussion}

\section{When to stop drying?}

309 This study indicates that it is more advantageous to stop the drying process before complete dehydration, as unnecessary re-adsorption of water is avoided. This procedure should in principle not compromise food safety, as

311 still a sufficiently low water activity can be obtained within the fruit after equilibration.

312 From the insights in the moisture redistribution, it seems that stopping the drying process when the (volume-

313 laveraged moisture content in the sample reaches the critical moisture content ( $\left.w_{m, c r i t}\right)$ (Var3_MCavg) is a good

314 compromise. For sufficiently small samples and dry environments $(R H<60 \%)$, the sample will be able to equilibrate rather fast to a safe water activity $\left(a_{w} \approx 60 \%\right)$ to avoid spoilage. Stopping when the (volume-)averaged water activity in the sample reaches 60\% (Var1_WAavg), implies that the sample still contains a quite large amount of water and, if applied, it should be further looked at in terms of food safety.

318 A remark should be made regarding the applicability of $w_{m, \text { crit }}$ as a stopping criterion. This study considered small temperature differences between the sample, the drying air and the ambient environment in which the fruit is placed in after drying. As the water activity and sorption isotherm are dependent on temperature, $w_{m, \text { crit }}$ during

321 drying can differ a bit from $w_{m, c r i t}$ at ambient temperature. Although this will not drastically impact the results, this 322 effect should be explored further.

\section{Model improvements}

324 The simulations enabled to evaluate different stopping criteria, which is less straightforward in experiments. The reason is that this has to be done in an offline manner as the samples need to be physically removed from the dryer.

329 The continuum model that is used to evaluate the drying process is known to many drying technologists and is rather straightforward to implement in commercial software (e.g. COMSOL Multiphysics). Model improvements can still be made to better represent the physical processes and further increase model realism. 
One of them is including tissue shrinkage, induced by moisture loss, as already implemented by other authors [2022]. As a result, the drying behavior will differ a bit, as shrinkage reduces the fruit volume. However, this would also require to determine new sorption isotherms and moisture permeability of different states of the shrunken tissue. This implies an extensive material characterization effort, which is rarely performed in drying engineering. In principle, adding shrinkage will not alter the conclusions of the present study, but will result in somewhat altered stopping times, as volume-averaged values are used.

Another model improvement is to implement a prediction of fruit quality evolution during drying. This can be done, for example, by implementing quality models, which predict degradation reactions based on temperature and water activity [23]. Finally, the material properties (moisture permeability, thermal properties) are taken constant. It would be useful to include the biological variability of these properties in the modelling, for example by using Monte Carlo simulations [24].

\section{Conclusions}

This study explored the impact of stopping the drying process, prior to complete dehydration, on the drying time and moisture redistribution kinetics inside the fruit during equilibration in the ambient environment. The three stopping criteria that were evaluated were based on the magnitude of the final water activity or the residual moisture content in the sample. These variants led to a decrease in residence time in the dryer of 70\% (Var1_WAavg), $2 \%$ (Var2_WAcore) and 24\% (Var3_MCavg), compared to full dehydration. Particularly variant Var3_MCavg was interesting as it reduced the residence time significantly. At the same time, this variant did not pose food safety issues, after the moisture was redistributed in the fruit during equilibration in the ambient environment. For this variant, drying is stopped when the average moisture content in the sample reaches the value corresponding to an equilibrium water activity of $60 \%$ in the sample, as determined from the sorption isotherm.

We also quantified how the humidity of the ambient environment in which the dried fruits are placed after drying affected the moisture redistribution kinetics. Furthermore the relation of the drying time to the drying air temperature was quantified for all stopping criteria.

This study gives a better quantitative insight in when fruit drying should be stopped, given specific drying conditions, as a way to reduce energy consumption (less rehydration) and processing time, and to improve product quality. The hygrothermal model allowed a detailed evaluation of the drying process and what happens within the fruit material during relaxation after stopping the drying process. Such modelling of the moisture redistribution kinetics could be of use for process optimization of intermittent drying, amongst others. 
363 We acknowledge the support of the World Food System Center (WFSC) of ETH Zürich

364 (www.worldfoodsystem.ethz.ch) and the support of the Swiss National Science Foundation SNSF (project 365 200021_160047).

\section{References}

368 [1] A.S. Mujumdar, Handbook of Industrial Drying, Fourth, CRC Press, Taylor \& Francis Group, Boca Raton, USA, 2014.

[2] T. Defraeye, Advanced computational modelling for drying processes - a review, Appl. Energy. 131 (2014) 323-344.

[3] C. Bonazzi, E. Dumoulin, Quality changes in food materials as influenced by drying processes, in: E. Tsotsas,

[4] I. Zlatanović, M. Komatina, D. Antonijević, Low-temperature convective drying of apple cubes, Appl. Therm. Eng. 53 (2013) 114-123. doi:10.1016/j.applthermaleng.2013.01.012. A.S. Mujumdar (Eds.), Mod. Dry. Technol. - Prod. Qual. Formul., Wiley-VHC Verlag GmbH, Weinheim, Germany, 2011: pp. 1-20.

[7] i. Ceylan, M. Aktaş, H. Doğan, Mathematical modeling of drying characteristics of tropical fruits, Appl. Therm. Eng. 27 (2007) 1931-1936. doi:10.1016/j.applthermaleng.2006.12.020.

D.A. Tzempelikos, D. Mitrakos, A.P. Vouros, A. V. Bardakas, A.E. Filios, D.P. Margaris, Numerical modeling of heat and mass transfer during convective drying of cylindrical quince slices, J. Food Eng. 156 (2015) 10-21. doi:10.1016/j.jfoodeng.2015.01.017.

A. Vega-Gálvez, K. Ah-Hen, M. Chacana, J. Vergara, J. Martínez-Monzó, P. García-Segovia, et al., Effect of temperature and air velocity on drying kinetics, antioxidant capacity, total phenolic content, colour, texture and microstructure of apple (var. Granny Smith) slices, Food Chem. 132 (2012) 51-59. doi:10.1016/j.foodchem.2011.10.029. Eng. 27(2007) 1931-1936. doi:10.1016/j.applthermaleng.2006.12.020.

8] G. Johann, M.L. De Menezes, N.C. Pereira, E.A. Da Silva, Comparing models to Neumann and Dirichlet conditions in grape seed drying, Appl. Therm. Eng. 93 (2016) 865-871. doi:10.1016/j.applthermaleng.2015.10.005.

[9] B. Sturm, A.M. Nunez Vega, W.C. Hofacker, Influence of process control strategies on drying kinetics, colour and shrinkage of air dried apples, Appl. Therm. Eng. 62 (2014) 455-460.

doi:10.1016/j.applthermaleng.2013.09.056. 
[10] J. a. Esfahani, H. Majdi, E. Barati, Analytical two-dimensional analysis of the transport phenomena occurring during convective drying: Apple slices, J. Food Eng. 123 (2014) 87-93. doi:10.1016/j.jfoodeng.2013.09.019.

[11] M. Ateeque, R.K. Mishra, V.P. Chandramohan, P. Talukdar, Numerical modeling of convective drying of food with spatially dependent transfer coefficient in a turbulent flow field, Int. J. Therm. Sci. 78 (2014) 145-157. doi:10.1016/j.ijthermalsci.2013.12.003.

[12] S. Ben Mabrouk, E. Benali, H. Oueslati, Experimental study and numerical modelling of drying characteristics of apple slices, Food Bioprod. Process. 90 (2012) 719-728. doi:10.1016/j.fbp.2012.02.001.

[13] J.C. Kurnia, A.P. Sasmito, W. Tong, A.S. Mujumdar, Energy-efficient thermal drying using impinging-jets with time-varying heat input - A computational study, J. Food Eng. 114 (2013) 269-277. doi:10.1016/j.jfoodeng.2012.08.029.

[14] K. Chapchaimoh, N. Poomsa-ad, L. Wiset, J. Morris, Thermal characteristics of heat pump dryer for ginger drying, Appl. Therm. Eng. 95 (2016) 491-498. doi:10.1016/j.applthermaleng.2015.09.025.

[15] T. Defraeye, P. Verboven, Convective drying of fruit: role and impact of moisture transport properties in modelling, Submitted. (2016).

[16] W. Aregawi, T. Defraeye, S. Saneinejad, P. Vontobel, E. Lehmann, J. Carmeliet, et al., Dehydration of apple tissue: Intercomparison of neutron tomography with numerical modelling, Int. J. Heat Mass Transf. 67 (2013) 173-182. doi:10.1016/j.ijheatmasstransfer.2013.08.017.

[17] A.K. Datta, Porous media approaches to studying simultaneous heat and mass transfer in food processes. I: Problem formulations, J. Food Eng. 80 (2007) 80-95. doi:10.1016/j.jfoodeng.2006.05.013.

[18] A. Kaya, O. Aydin, I. Dincer, Numerical modeling of heat and mass transfer during forced convection drying of rectangular moist objects, Int. J. Heat Mass Transf. 49 (2006) 3094-3103. doi:10.1016/j.ijheatmasstransfer.2006.01.043.

[19] T. Defraeye, B. Blocken, J. Carmeliet, Analysis of convective heat and mass transfer coefficients for convective drying of a porous flat plate by conjugate modelling, Int. J. Heat Mass Transf. 55 (2012) 112-124. doi:10.1016/j.ijheatmasstransfer.2011.08.047.

[20] W. Aregawi, T. Defraeye, P. Verboven, E. Herremans, G. Roeck, B. Nicolai, Modeling of coupled water transport and large deformation during dehydration of apple tissue, Food Bioprocess Technol. 6 (2013) 19631978. doi:10.1007/s11947-012-0862-1.

[21] T. Gulati, A.K. Datta, Mechanistic understanding of case-hardening and texture development during drying of food materials, J. Food Eng. 166 (2015) 119-138. doi:10.1016/j.jfoodeng.2015.05.031.

[22] M.E. Katekawa, M.A. Silva, A review of drying models including shrinkage effects, Dry. Technol. 24 (2006) 5- 
424 [23] M.A.J.S. Van Boekel, Kinetic modeling of food quality: A critical review, Compr. Rev. Food Sci. Food Saf. 7 (2008) 144-158.

426 [24] T. Defraeye, G. Houvenaghel, J. Carmeliet, D. Derome, Numerical analysis of convective drying of gypsum boards, Int. J. Heat Mass Transf. 55 (2012) 2590-2600. doi:10.1016/j.ijheatmasstransfer.2012.01.001. 